\title{
Federico de Onís (1885-1966)
}

El I4 de octubre de I966, en la ciudad de San Juan de Puerto Rico, el doctor Federico de Onís, "el salmantino universal", puso fin a su vida, "por acto de su voluntad", según un escueto cable de Jaime Benítez, rector de la Universidad de Puerto Rico. Pasaba ya de los ochenta años de edad, pero quienes le trataban afirman que "estaba tan fuerte, ruidoso, cortante y ágil como en su juventud" (Luis Alberto Sánchez). Su desaparición, y en forma tan inesperada, ha causado profunda consternación en los círculos culturales del mundo hispánico y entre los estudiosos de la cultura y las letras de lengua española. Federico de Onís tenía en todas partes amigos sinceros, admiradores fervorosos y discípulos que le honraban. Su recia personalidad de investigador, maestro y crítico literario le había colocado en un sitio prominente de guía espiritual de lo que podríamos llamar "la España nueva", y de consejero mayor para quienes prolongan hoy esa España viva - de "vividura" profunda y real - sobre todo en este Nuevo Mundo en que vivimos. De ahí que no haya sido nunca un "exilado", de esos que sólo quieren afirmar la desgarradura de un ser que jamás podría desmembrarse. Por el contrario, su acción, siempre ejemplar y concorde con una doctrina de integración creadora, fue la de un continuador, y saludablemente positiva, no cerrada a un estrecho casticismo de academia o consigna, sino abierta a todas las renovaciones que fecundan los predios tradicionales. Si alguna vez afirmó que "España fue siempre un país de frontera", debe entenderse que esa "frontera" no podía ser comprendida como término de límite que separa y divide, sino como una puerta de comunicación generosa y de fraternidad comprensiva. De ahí también su profunda visión de lo hispánico como sentido universal de un modo de ser y una peculiar expresión de cultura. Este ser y esta cultura, de la que Federico de Onís es uno de sus más genuinos representantes, es la que mantiene sin desmayos ni resquemores el nombre de España en el mundo, y en especial, 
entre sus hijos de América. Lejos estaba este gran español hispanoamericanizado de cualquier imperativo colonizante o de agresivos colonialismos imperialistas. "La eternidad de España en América" o, simplemente, España en América (título del corpus definitivo en donde reunió lo fundamental de su obra) es lo que don Federico quería salvar y mostrar, en medio de la "originalidad esencial de la cultura de este continente" 1 Ya no se trata de ver a América como una simple "expansión de Europa", ni menos, claro está, como un regreso a las semillas indigenas; lo que ahora importa es ver la validez que una y otra tienen para la determinación de eso que puede ser la originalidad hispanoamericana dentro de una variedad hispanoeuropea. Para ello empieza por abandonar los patrones europeos con que hasta entonces se venía interpretando a América; e inicia así la "visión americana" - lo que Alfonso Reyes llamó "la inteligencia americana"como un nuevo modo de interpretar la cultura, sea ésta la nuestra o la ajena. Mas Federico de Onís no sólo afirma la diferenciación entre España y América ("registrada en el primer documento de la literatura hispanoamericana"), sino, por descontado, entre "Europa y América, diferenciación que, por otra parte, deja el camino abierto a una integración de las Américas de hablas hispánicas e inglesa. Se comprende que una proclamación de tal índole -y de modo tan rotundo- pueda provocar alguna encubierta suspicacia. Pero Onís no es de los que hacen afirmaciones fáciles. Detrás de él está la erudición de Menéndez y Pelayo, el método científico de Menéndez Pidal y la escuela del Centro de Estudios Históricos y, sobre todo, el sentir "intrahistórico" de su maestro Unamuno y la "Generación del 98", buscadores sin tacha de la España profunda y leal tanto como de la América primordial y fecundante. Por esta vía se justifican también dos de las más arriesgadas conclusiones del maestro del Hispanic Institute: la de que la permanencia de España en América tendremos que hallarla "no en lo que España hizo y dejó en América, sino en lo que los americanos crearon por sí mismos diferenciándose de los españoles", y la de que por esa penetración de lo original americano podremos llegar a entender mejor lo europeo. Es lo que tratamos de hacer quienes seguimos su propuesta. Sarmiento, Martí, Darío, la novela y la poesía hispanoamericanas del siglo $\mathrm{XX}$ son pasos que jalonan esa visión y esa originalidad. Onís, ojo avizor

1 España en América (Puerto Rico: Edición de la Universidad, 1955), p.

Otras obras de F. de Onís son: Disciplina y rebeldia (Madrid: Residencia de Estudiantes, 1915); Ensayos sobre el sentido de la cultura española (Madrid: Residencia de estudiantes, 1932); Antología de la poesía española e bispanoamericana. 18821932 (Madrid: Centro de Estudios Históricos, 1934); Antbologie de la poésie latino-américaine (Paris: UNESCO, 1956). La mayoría de estos estudios, excepto los textos antológicos de los poetas, figura en España en América, así como pró. logos a ediciones de autores españoles para "La Lectura" y para Heath and Co. 
sin par, su intérprete y su promotor incondicional. Lección que amerita el paso de un hombre genial junto a nosotros. $Y$ dejar de venerarle sería una incongruencia fatal. Todo lo demás $-y$ es mucho lo que queda de su obra - no cabe en los límites de esta nota, que no queremos sea una mera cortesía de necrólogo, sino el tributo sincero de nuestra agradecida admiración hispanoamericana. El creador del primer Instituto Hispánico en América, de la primera Revista Hispanica Modena y de la primera Antologia de la poesía española e bispanoamericana merece el homenaje universal" de nuestra América y un sitio de honor en el corazón de cada uno de nosotros por lo mucho que nos enseñó y por el generoso desprendimiento con que se dio a esa América ideal de sus sueños y esperanzas.

ALFREDO A. RogGIANo

University of Pittsburgh

\section{DATOS BIOGRAFICOS DE FEDERICO DE ONIS, ESCRITOS POR EL MISMO}

Nació en Salamanca el 20 de diciembre de 1885 y alli estudió en el Instituto y la Universidad basta graduarse de Licenciado en Letras en 1905. Su principal maestro fue don Miguel de Unamuno, con quien tuvo relación intima desde los seis años. En 1905 fue a Madrid a estudiar el año del doctorado, y entonces empezó su relación con su maestro don Ramón Menéndez Fidal, continuada en el Centro de Estudios Históricos desde su fundación. Entre tanto bizo oposiciones en 1907 al Cuerpo de Arcbiveros, Bibliotecarios y Arqueólogos, y fue destinado León y en 1908 trasladado a Oviedo. Ese mismo año obtuvo el grado de Doctor en Letras, y conoció a su otro amigo y maestro José Ortega y Gassett, que acababa de regresar de Alemania y empezaba entonces a escribir. En 1909 fue premiado en el Concurso de la Real Academia Española por su obra La lengua de Salamanca en la Edad Media, que por querer ampliarla no ba llegado a publicar. Ese mismo año fue nombrado Auxiliar en la 
Facultad de Filosofia y Letras de la Universidad de Oviedo, y tuvo a su cargo la catedra de Lengua y Literatura Españolas, entonces vacante, siendo éste el principio de su profesorado. En 1911 fue nombrado por oposición catedratico de Lengua y Literatura Españolas y desempeñó esta câtedra en la Universidad de Oviedo basta 1915, dividiendo su tiempo entre Ovieldo y Madrid, donde estaba agregado al Centro de Estudios Históricos y era además Director de Estudios de la Residencia de Estudiantes recién fundada. En 1915 fue trasladado como cateldrático a la Universidad de Sallamanca.

En setiembre de 1916 fue a Nueva York invitado por Columbia University para organizar en ella los estudios españoles, que en aquel momento babian crecido desmesurdamente con motivo de la primera guerra mundial. Fue allá con la idea de estar un año, con licencia, y regresar a su cátedra de Salamanca. Pero al fin de aquel año vio que debia regresar a Nueva York por otro año y le fue prorrogada la licencia. Después de estos dos años pensó en quedarse por un periodo más largo y solicitó licencia por tres años. Cinco años de trabajo en Columbia le decidieron a continuar alli permanentemente, y en 1921 solicitó la excedencia como catedratico en España. Así fue como la visita de un año se prolongá por treinta y ocbo, y acabó siendo permanente.

Conforme a este cómputo la vida del autor estâ dividida en dos etapas: la española, de treinta años, la americana, de treinta y ocho. En rigor este cambio geográfico y espiritual no significó ruptura entre las dos, porque la razón que babía en el fondo de mi propósito creciente de quedarme en América era el becbo, no ya de que mi trabajo en ella era totalmente español, sino el de que en este continente me sentía más en el centro de España que cuando esiaba en España misma. Ya antes de salir de España sentia la atracción de la América española como razón última del ser bistórico de España. Mi trato con Unamuno me babia preparado para conocerla, $y$ ésta es quizá mi mayor deuda para con él. Y también lo es para con los Estados Unidos el que viviendo en ellos be poldido estar en contacto constante con el mundo bispanoamericano y consagrarme al estudio y la enseñanza de su cultura. Nueva York es cada vez más el centro de comunicación con las otras Américas, y además de conocer a los bispanos que alli viven o por alli pasan, be podido conocerlos en sus países. En diversas ocasiones be estado como profesor visitante y conferenciante en las Universidades del Sidoeste español de los Estados Unidos y en casi todos los paises bispanoamericanos. 
Al mismo tiempo mantenia relaciones estrechas con España como representante en los Estados Unidos de la Junta para Ampliación de Estudios y la Junta de Relaciones Culturales, y mediante viajes repetidos a España, Inglaterra y Francia, basta que la guerra civil española y la segunda guerra mundial los interrumpieron. Fui un año profesor visitante en Oxford $y$ di conferencias en otras Universidades inglesas y francesas. En España renovaba mi relación personal con los antiguos maestros y compañeros en los centros científicos y literarios, y mantenía mi contacto con la tierra y el pueblo baciendo estudios folklóricos mientras descansaba de otros trabajos en las debesas de Salamanca y en las sierras de Avila. En los Estados Unidos fundé con otros en 1920 el Instituto de las Españas para encauzar las relaciones triangulares entre España, Hispanoamérica y los Estados Unidos.

(De España en América, pp. 8-9). 
